\title{
https://doi.org/10.48009/2_iis_2006_101-104 \\ COMPUTER-SUPPORTED COOPERATIVE WORK: A COLLABORATIVE VIEW
}

\author{
Kristi Berg, Minot State University, kristi.berg@minotstateu.edu \\ Dr. Lori Willoughby, Minot State University, lori.willoughby@minotstateu.edu \\ Dr. John Girard, Minot State University, john@johngirard.net
}

\begin{abstract}
The collaboration which has emerged through the use of computers is referred to as computersupported cooperative work. This phenomenon of collaboration via the computer was designed to support users as they engage in the electronic exchange of information with work teams and colleagues. This paper takes a macro view of computer-supported cooperative work, expressly in the area of best practices within collaborative work. The research stems from the creation of a bachelor's of science degree in virtual business in a technology department at a Midwestern university. In addition, the department also offers three undergraduate and one graduate technology degrees online which incorporate computer-supported cooperative work across the curriculum. A literature review exploring the value of computer-supported cooperative work will include a look at current themes such as where it's happening, dangers, business value, and successful implementations. Examples of how several organizations have successfully implemented collaborative environments will support this analytical research. The research will conclude by defining best practices, which when utilized will support a successful collaborative environment.
\end{abstract}

Keywords: Computer-Supported Cooperative Work (CSCW), Collaboration

\section{COMPUTER-SUPPORTED COOPERATIVE WORK}

The phenomenon of collaboration via the computer is known as computer-supported cooperative work (CSCW). CSCW was designed to support users as they engage in the electronic exchange of information with work teams and colleagues. CSCW brings together researchers and developers from different areas, "merging issues, approaches, and languages" [7]. The phrase computer supported cooperative work was coined over a decade ago and today remains a term which has many diverse, yet similar representations among researchers and practitioners. One of those many representations of CSCW comes from the practice of collaboration.
The word "office" no longer takes on the connotation of an area surrounded by four walls within a fixed location. Today's office can be defined by wherever a laptop can go. Workers have mastered content creation and are communicating more efficiently than ever before, yet they desire more. These workers want the ability to share information both inside and outside of their organizations and across boundaries; they desire collaboration. While email has more than proven its efficiency, it remains centralized and does not facilitate dynamic interaction between groups of workers. Collaborative tools, on the other hand, "are designed to let people meet in a virtual environment, post documents, download them, deal with version control and enable chat room functions" [19].

Kafentzis, Mentzas, Apostolou, and Gergolios define collaboration as "all the services that support users to work together while fulfilling a common task" [9]. $\mathrm{CSCW}$ is one of these services which enable users to work together via the use of technology. This type of work is normally supported by groupware, which enables communication, cooperation and coordination to occur between work group members [9]. In organizations the groupware can increase the chances of collaboration as it "is built on the premise that it coordinates activities across time and space" [4]. While the coordination of collaborative activities can be facilitated through the use of groupware, there must also be a culture which is in support of collaborative activities.

Organizations that embrace these activities realize that collaboration is appealing because it has the potential to break down geographical barriers and to increase the efficiency of teamwork through the use of virtual workspaces. These virtual workspaces consist of shared items ranging from document libraries to calendars to announcements, all tools which enable collaboration to happen. Putting a collaborative information network into practice is not without challenges; however, reward usually never comes without a bit of risk. Without venturing into the world of collaborative technologies, the risk of missing an evolution may be even greater. Anson and Munkvold described a prediction that was made by the Gartner Group in 1999. The prediction was that 
"collaborative commerce (c-commerce) would be the next evolution in eBusiness applications, creating collaborative supply chains that support dynamic interaction among employees, business partners, and customers" [2]. The environment envisioned was based on Web functionality and on- and off-line collaboration by team members in different locations.

\section{THEMES IN COMMUNITIES OF PRACTICE}

Collaboration has occurred in part as a necessity to keep up with the rapid pace of today's work place. This pace encourages employers to be creative with conditions such as cost, flexibility, and time. Technology has also enabled organizations to spread out geographically; however, this distance comes with a price. However, through the use of collaborative tools travel expenses can be minimized. Organizations also need to realize the importance of flexibility, and collaborative tools open up the possibility to embrace this flexibility. Sometimes this involves employees who telecommute or short-term joint ventures with individuals or business outside of the organization. Time is also a commodity which businesses value saving. A collaborative IT solution can be deployed quickly without zapping a budget.

Collaboration is happening among organizations around the globe. Collaboration among competitors may have a frightening ring; however, it is currently being successfully accomplished among two very well known contenders. Proctor and Gamble and Clorox are two organizations that maintain fierce competition in the cleaning products arena. However, when Proctor and Gamble developed a new technology in plastic wrap, called Press'n seal, they realized quite quickly that without their own line of plastic wrap products, this new product would not be well received by consumers. So, Proctor and Gamble contacted Clorox and through a collaborative process was able to strike a nice deal for both organizations. The deal gave Proctor and Gamble ten percent of Clorox's successful Glad operations. The deal enabled Clorox the introduction of a new product and they had the opportunity to share in the research and development network of Proctor and Gamble for plastic products. This collaborative venture between these fierce competitors has also produced a new trash bag called ForceFlex. Proctor and Gamble has long been a proponent of collaboration within their organization. Their new found success with collaboration externally has encouraged them to go further by making collaboration a goal within research and development innovation [6].
The retail industry family has been identified as an area in which the lack of collaboration is a cause for concern. While collaborative technology has been advancing outside of this industry, the industry itself is plagued by outdated processes. Rosenblum [17] has extensively examined the retail sector, finding common themes such as retailers communicating and collaborating better with outside vendors than with those who are right inside their organizations; email and intranet deployment without benefits; and lack of ability when it comes to product sharing, inventory, and customer data across organizations. While it seems the lack of collaboration would be simple to fix, it remains just the opposite. The lack of strong support for collaboration in the retail industry drives this lack of support. A proponent needs to evolve from an organization in the industry and set an example of how collaboration could lead to better internal communication, customer relations, and profits. Rosenblum [17] recommends those in the retail family to first consider the process and adoption of appropriate technologies, then to deploy them in a beneficial manner in actual retail stores, and finally look at how communication works and implement proactive ways to use the collaborative tools to facilitate communication.

The win-lose mentality is a danger of collaboration. In the past when organizations have worked together, the end result was about who came out on top. Caution is placed when it comes to levels of trust. Operating under the umbrella of caution can decrease the benefits of collaborative relationships among organizations. The ownership of the property created during collaboration is another dangerous area. Intellectual property ownership is the part of the venture which needs to be negotiated ahead of time to avoid a strain on the collaborative relationships down the road. In cases where intellectual property is critical to the organization, then collaboration in those areas is probably not the best answer. Integration is one danger that can cause a cease in collaborative efforts quickly. Coordinating the sharing of data between systems is also something that organizations must configure at the onset of a collaborative relationship. The security and firewall issues should be realized through an orientation process before the actual live collaboration occurs. Avoiding these seemingly simple dangers can lead to successful collaborative opportunities [17]. When striving to incorporate collaboration, a struggle often stems from attempts to get senior management to realize the business value of collaboration. The benefits from collaboration are not immediate and may seem hard to measure; however, "the indirect 
benefits may exceed the gains in efficiency from traditional investments in automation" [3].

Successful collaboration begins with the ability of the organization to effectively gauge the impact of collaboration. Conducting an analysis to determine the collaborative needs is often a good place to begin; however, many organizations find that collaborative needs are already being met through a menagerie of different efforts by a variety of employees. Evaluating the tools already in place provides a good basis to determine what works and what doesn't work. Moving toward a successful collaboration platform for an organization may require getting rid of what doesn't work and building upon what works; or in some cases, it may involve a complete overhaul of the collaboration foundation. Developing scenarios in which collaboration will be utilized within the organization is the first step toward success. These scenarios can help determine how processes and tools might function within a collaborative environment. The types of collaborative tools or systems needed may also evolve from scenario situations and help drive decisions regarding the type of architecture and system needed for the organization.

Successful collaboration depends upon internal and external variables within organizations. "Internal collaboration is a construct defined as an affective, mutually shared process where two or more departments work together, have mutual understanding, have a common vision, share resources, and achieve collective goals. External collaboration is defined similarly to internal collaboration, with the exception that the focus of collaboration is between two or more firms, rather than departments" [18]. Internal collaboration is supported by the sharing of cross-functional integrated data. External collaboration supports this function as it shares this data with many participating agents. Successful collaboration rests on the foundation of competence as organizations look to share information while saving time and cutting costs. Effectively gauging the impact of collaboration becomes the challenge for many organizations.

\section{BEST PRACTICES}

Pay-as-you-go shared working environments are practiced in effort to minimize the need or difficulty caused by systems integration worry. This practice avoids dealing with the hassles of technology integration or a hefty investment in technology. ForumPass is a collaborative tool which fits this desired environment. It is a membership-based network which can link organizations, suppliers, and customers. The functionalities of the tool include virtual workspaces, web conferencing, online meeting. This tool is currently being used among the aerospace organizations of BAE, Boeing, Lockheed Martin, Raytheon, and Rolls-Royce. This product serves these geographically dispersed organizations by enabling project management flexibility, integration of teams, and efficiency across all aspects of a projects life-cycle.

Mutual value among customers, suppliers, partners, and colleagues was desired when CareGroup Healthcare System in Boston set out to deploy a collaborative network [13]. This Web-based service was created to strengthen the communication between physicians, hospital, and patients. Baby CareLink, one component of the overall system, was created with parents and patients in mind. This component enables parents who must leave their premature or ill babies at the hospital and travel home, sometimes miles away, to view their babies via their home computer. The staff provides pictures and vital updates around the clock on their patients. Once the babies go home, parents and doctors can also stay in contact through videoconferences. This technology is enabling patients and parents to be home sooner, but also keep the doctors informed. This system enables a better experience for families and creates a clear financial advantage when considering the cost in the neonatal unit is approximately $\$ 5000$ per day [13].

New York ad agency Ogilvy \& Mather has been in business for years and maintains a high reputation among its clientele. IBM happens to be one of their clients and expressed a desire for the ability to collaborate during the design process, rather than using express mail to proof images. With the help of IBM, the agency created a system based on Lotus Notes which enables clients to view files online. Due to the sensitive nature of the information with which the agency deals, security was a main issue. The agency has deployed software protections, firewalls, and a virtual private network Internet connection. In addition, the agency will give the desired level of security as requested: in some cases work is kept on a separate server with a dedicated line at headquarters. The agency has since contracted with another software designer and customized the system to meet their growing needs and is now touting collaboration during their sales pitch [13].

"At GlaxoSmithKline they know that increasing the amount of information without tools to manage it is a formula for failure" [13]. GlaxoSmithKline is a pharmaceutical company which employs thousands 
of researchers who are working on research and performing tests to develop new medicines. Information is stored in several different formats in databases. Recently the company created a Web tool to search the databases and external sources to create a list of work which has been performed. This innovative development is part of an overall plan aimed at speeding up research and development [13]. Trust and truth are keys within collaborative relationships. Organizations "have to establish and nurture nonadversarial relationships, and that can be difficult because business historically is built on competition" [12]. Owens \& Minor is a healthcare products distributor based in Virginia and they know a thing or two about collaboration and trust. They have an Internet order fulfillment system with the product catalog linked to Kimberly-Clark, a Georgia healthcare business. The integration of these systems enables customers to have a direct link to desired products and product information. The relationship between the two companies is built upon collaboration and trust that each is doing their best to cooperate in effort to better manage inventory levels and deal with customer demand. Frequent meetings are held and communication is regular, with efforts focused on nurturing the relationship [12]. "Collaboration, based on the idea that the strength of the whole is greater than the sum of the parts, requires virtual integration among partners" [12].

This paper provided an opportunity to view CSCW through the lens of collaboration. Specific themes in collaboration such as where it's happening, dangers, the business value, and successful collaboration were explored. Several best practice examples rounded out the paper providing a wealth of information in the area of collaboration. With the abundance of research in this area, this paper has provided the literature review for a future research study exploring uses of specific collaboration tools. This study will attempt to capture the characteristics of employees in a Midwestern business community as they collaborate inside and outside of their organizations.

\section{REFERENCES}

1. Anson, R. \& Munkvold, B. E. (2004). Beyond face-to-face: A field study of electronic meetings in different time and place modes. Journal of
Organizational Computing and Electronic Commerce, 14(2), 127-152.

2. Burton, B. (2005). Best practices for delivering business value from collaboration. Gartner Research (ID Number: G00127844).

3. Clarke, P. \& Cooper, M. (2000). Knowledge management and collaboration. Proceedings of the Third International Conference on Practical Aspects of Knowledge Management, Basel, Switzerland.

4. Dragoon, A. (2004). A travel guide to collaboration. CIO. Retrieved on December 1, 2005

from http://www.cio.com/archive/111504/guide.html.

5. Grudin, J. (n.d.). CSCW: History and focus. University of California, Irvine. Available online http://research.microsoft.com/ jgrudin/past/Pape rs/IEEE94/IEEEComplastsub.html.

6. Kafentzis, K., Mentzas, G., Apostolou, D. \& Georgolios, P. (2004). Knowledge marketplaces: Strategic issues and business models. Journal of Knowledge Management, 8(1), 130-146.

7. McClellen, M. (2003). Collaborative strategies: Outside-the-box manufacturing. Optimize. Retrieved on December 1, 2005 from http://www.optimizemag.com/issue/017/collabor ative.htm.

8. McGee, M. \& Murphy, C. (2001). Collaboration is about more than squeezing out supply-chain costs. Information Week. Retrieved on November $\quad 15, \quad 2005$ from http://www.informationweek.com/shared/printab leArticle.jhtml?articleID=6508328.

9. Rosenblum, P. (2005). The last frontier: Collaboration in the retail enterprise. Aberdeen Group. Retrieved on December 1, 2005 from http://www.microsoft.com/industry/retail/busines svalue/internalcollababstract.mspx.

10. Sanders, N. R. \& Premus, R. (2005). Modeling the relationship between firm IT capability, collaboration, and performance. Journal of Business Logistics, 26(1), 1-23.

11. Sweeney, Terry (n.d.). Open-door collaboration - Helping engineers and product developers gain new levels of efficiency. Retrieved on November 14, 2005 from http://www.microsoft.com/business/executivecir cle/content/article. aspx $?$ cid $=1369 \&$ subcatid $=302$ 